\title{
e-Sinais: Software Tradutor de Português Sinalizado para Sinais em LIBRAS
}

\author{
Igor Q. Silva ${ }^{1}$, Bruno S. Mascarenhas ${ }^{2}$, Saionara S. Araújo ${ }^{3}$, \\ Daniela G. S. Freitas ${ }^{4}$, Pablo F. Matos ${ }^{5}$
}

${ }^{1}$ Discente Superior em Ciência da Computação, ${ }^{2}$ Discente Técnico em Eletrônica Integrado, ${ }^{3}$ Discente Superior em Sistemas de Informação, ${ }^{4}$ Intérprete de LIBRAS, ${ }^{5}$ Docente de Informática

${ }^{1}$ Universidade Estadual do Sudoeste da Bahia (UESB)

Estrada Bem Querer - 45.083-900 - Vitória da Conquista - BA - Brasil

${ }^{2345}$ Instituto Federal de Educação, Ciência e Tecnologia da Bahia (IFBA)

Av. Amazonas, 3150, Zabelê - 45.075-265 - Vitória da Conquista - BA - Brasil

\{igorqsilva, brunomask, narabdo, danielasilveira08, pablofmatos\}@gmail.com

\begin{abstract}
The e-Signs is an educational software that performs the translation of Signaled Portuguese for signs in LIBRAS and it aims providing to deaf the learning of new words. The idea is that deaf will be independent of a human translator/interpreter in the day-to-day tasks and he may perform their studies or to work with the help of the tool. Moreover, the software may also serve as teaching tool of LIBRAS for listeners, in which it helps the integration of deaf and hearing communities. The e-Signs offers other features such as the addition of new signs inherent of each region and the export of signs to PDF file, which it allows the printing and distribution of signs.
\end{abstract}

Resumo. O e-Sinais é um software educacional que realiza a tradução de Português Sinalizado para sinais em LIBRAS e tem como objetivo proporcionar aos surdos o aprendizado de novas palavras. A ideia é que nas tarefas do dia a dia o surdo seja independente de um tradutor/intérprete humano e consiga realizar seus estudos ou trabalhar com o auxilio da ferramenta. Ademais, o software pode servir também como ferramenta de ensino de LIBRAS para ouvintes, em que auxilia a integração das comunidades surda e ouvinte. O e-Sinais disponibiliza outros recursos como a adição de novos sinais inerentes de cada região e a exportação de sinais para arquivo PDF, que permite a impressão e a distribuição dos sinais.

\section{Introdução}

A Língua Brasileira de Sinais (LIBRAS), utilizada pelos surdos, é uma língua natural e, portanto, apresenta os seguintes níveis linguísticos: fonológico, morfológico, sintático e semântico [1]. A LIBRAS é diferenciada da Língua Portuguesa por sua forma de expressão ser visual-espacial e também por possuir estruturas gramaticais diferentes. Neste trabalho, considera-se a expressão Português Sinalizado como sendo um sistema de notação em palavras que tem como característica a apresentação dos verbos no infinitivo e a inexistência de alguns conectivos (conjunções e preposições). Essas diferenças são um dos pontos que dificultam a compreensão, por um surdo, de um texto escrito em Português.

Segundo censo de 2010 pelo IBGE [2], cerca de 9,7 milhões de brasileiros possuem deficiência auditiva, o que representa $5,1 \%$ da população total. Na população com deficiência, $61,1 \%$ não possuem o fundamental completo, $14,2 \%$ possuem o fundamental completo, $17,7 \%$, o médio completo e 6,7\%, o superior completo [3]. Segundo a FENEIS [4], quase dois milhões de brasileiros surdos não são alfabetizados em Português escrito, que é sua segunda língua, e se comunicam exclusivamente por meio da LIBRAS. A falta de acessibilidade a textos escritos, além de restringir o acesso à informação para a comunidade surda, é um grande agente desmotivador.

Há alguns softwares que lidam com a tradução textual de Português para Português Sinalizado $[5,6,7]$. Porém, o uso desta funcionalidade exige dos surdos um conhecimento de compreensão dos textos em Português, o que não é constatado na prática, já que os surdos necessitam de uma metodologia adequada para compreender o Português escrito [8]. 
O software LIBROL [5], desenvolvido pelo nosso grupo de pesquisa, visa a realizar a tradução de textos em Português para o Português Sinalizado, mais simples de ser compreendido pelo surdo. Após o desenvolvimento do software LIBROL, foi realizada uma avaliação da compreensão de textos jornalísticos em Português, em LIBROL e em Português Sinalizado por Estudantes Surdos [9]. Percebeu-se que, com o uso da ferramenta, houve uma melhora na compreensão dos textos escritos por parte dos leitores surdos. Porém, em alguns casos, os surdos não compreendiam o texto, nem em Português Sinalizado, nem em LIBROL, muito menos em Português escrito. Isso aconteceu devido ao desconhecimento das palavras presentes nos textos.

Nesse contexto, surgiu a ideia de criar um software complementar ao LIBROL, denominado e-Sinais, software tradutor de Português Sinalizado para sinais em LIBRAS, que tem o intuito de possibilitar ao estudante surdo aprender novas palavras independentemente de um tradutor/intérprete humano, o que contribui para aumentar o vocabulário e, por conseguinte, a compreensão dos textos. Ademais, o software pode ser usado como ferramenta de ensino de LIBRAS para ouvintes, o que pode propiciar a integração das comunidades surda e ouvinte. $\mathrm{O}$ restante deste artigo está estruturado como segue. Na Seção 2, são resumidos os trabalhos correlatos. Na Seção 3, são apresentadas as características do software e-Sinais e na Seção 4, são apresentadas as Considerações Finais e os Trabalhos Futuros.

\section{Trabalhos Correlatos}

Os trabalhos encontrados na literatura têm como objetivo a tradução entre a Língua Portuguesa e a LIBRAS a fim de auxiliar na comunicação entre surdos e ouvintes $[6,10,11]$, a tradução textual do Português para o Português Sinalizado $[5,6,7]$ ou o ensino-aprendizagem de LIBRAS [5, 12, 13].

Dentre os trabalhos pesquisados, ressalta-se o Teaching Hand, o Luz, Câmera, Libras! e o ProDeaf. O Teaching Hand [13] é um software que auxilia crianças surdas no aprendizado da gramática da Língua Portuguesa por meio da associação de imagens e sinalizações. O Luz, Câmera, Libras! [12] é um software direcionado para o aprendizado de sinais por meio do lúdico, no qual os participantes devem adivinhar os sinais elaborados por outro participante. O jogo se baseia em vídeos feitos pelos jogadores. O ProDeaf [6] é o software mais completo encontrado na literatura. Contém um conjunto de software que possibilita a tradução de texto e voz de Português para LIBRAS, com o principal objetivo de permitir a comunicação entre surdos e ouvintes. Ademais, o ProDeaf tem soluções para tradução textual com a possibilidade de incluir sinais e consultar o dicionário de palavras. Porém, a tradução é limitada a 140 caracteres, não é possível exportar os sinais para nenhum tipo de arquivo e não tem o foco no ensino-aprendizagem de LIBRAS.

\section{Software e-Sinais}

O software e-Sinais tem como objetivo possibilitar ao surdo interpretar palavras do Português Sinalizado para sinais em LIBRAS, o que viabiliza a aprendizagem de novas palavras com o intuito de obter a independência de um tradutor/intérprete humano nas tarefas do dia a dia, seja na vida profissional ou acadêmica. O e-Sinais tem como entrada de dados palavras em Português Sinalizado e como saída os sinais correspondentes em LIBRAS no formato de imagem (Figura 1). O e-Sinais foi desenvolvido utilizando a Linguagem de Programação Java [14] por ser gratuita e portável para qualquer sistema operacional. Está disponível sob a licença GNU AGPL e pode ser baixado em https://sourceforge.net/u/e-sinais/profile/.

A tradução é realizada em três etapas: (i) divisão do texto em palavra por palavra; (ii) busca destas palavras no banco de dados; (iii) apresentação do sinal retornado pelo banco de dados na tela do software. A divisão do texto em várias palavras separadas é a primeira etapa da tradução. Para realizar essa tarefa, foi necessário criar um array de variáveis do tipo string com as palavras isoladas. O sistema de gerenciamento de Banco de Dados Relacional (BDR) utilizado foi o HSQLDB [15], escolhido por ser desenvolvido em Java, por ser pequeno, por executar na memória principal, sendo assim não necessita de instalação e, por fim, por ser de fácil utilização. A tabela criada no banco de dados possui dois atributos: "palavra", na qual são armazenadas as palavras em Português Sinalizado; e "sinal", na qual são armazenados os endereços das imagens contendo os sinais. 


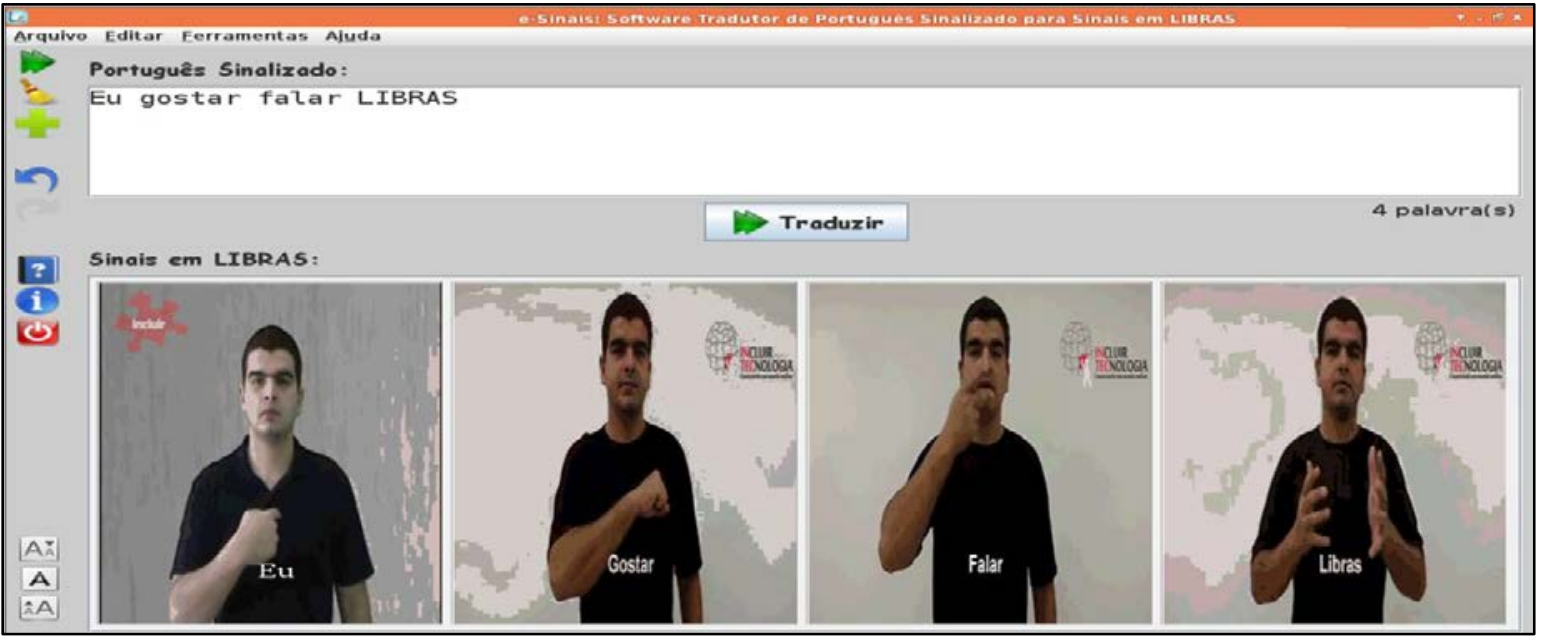

Figura 1. Interface do software e-Sinais. Fonte. Próprio autor.

Para realizar a busca no banco de dados, foi utilizado o seguinte comando SQL (Linguagem de Consulta Estruturada):

SELECT sinal FROM public.tabela WHERE palavra = ' $\mathrm{x}$ ';

Os atributos "sinal" e "palavra" representam as colunas, a tabela "public.tabela" se refere à tabela onde os dados estão armazenados e, ' $x$ ' representa a palavra sobre a qual será realizada uma busca no banco de dados. Este comando retornará o endereço em que se encontra o sinal correspondente à palavra ' $x$ '. Para finalizar o processo da tradução, o endereço retornado é utilizado para carregar a imagem e apresentá-la na tela do software. Os sinais podem ser armazenados no BDR por imagens estáticas (JPG e PNG) ou por imagens animadas (GIF).

A versão atual do software contém 811 sinais no formato de imagem animada GIF, as quais foram obtidas do Glossário de LIBRAS do Incluir Tecnologia ${ }^{1}$. Foi necessário converter os arquivos disponíveis em vídeos para o formato GIF e, em seguida, redimensionar as imagens. Os sinais que representavam frases ou palavras compostas e os verbos conjugados foram excluídos. Com relação às palavras que possuíam mais de uma representação em LIBRAS (sinônimos), decidiu-se utilizar somente um sinal e excluir os outros. Ademais, para palavras diferentes que possuíam o mesmo sinal, optou-se por nomear o sinal com um código único e relacioná-lo a todas as palavras correspondentes.

Além do recurso de tradução, o e-Sinais possui mais dois outros importantes recursos: adição de sinais e exportação de sinais para PDF. O primeiro recurso possibilita ao usuário adicionar um novo sinal ou alterar um sinal cadastrado. Isso é útil para suprir a falta de algum sinal no banco de dados, o que viabiliza o acréscimo de sinais inerentes de cada região. $O$ segundo recurso permite que as palavras traduzidas para sinais sejam exportadas para um arquivo PDF (Formato Portátil de Documento), o que permite tanto que os sinais sejam distribuídos para os que não possuem o software quanto sejam impressos e distribuídos em salas de aula e demais ambientes a fim de viabilizar a acessibilidade aos surdos.

Para imagens estáticas no formato JPG e PNG, o programa apenas gera uma imagem do sinal no arquivo PDF. Porém, para imagem no formato GIF, o programa gera uma série de imagens sequenciais que são selecionadas de 4 em 4 frames. Optou-se por esta implementação para que o arquivo PDF não fique muito extenso, o que inviabiliza a tradução de sequências longas de palavras. É importante destacar que não há restrição de quantidade de palavras a serem traduzidas. É possível mostrar uma quantidade ilimitada de sinais devido à criação dinâmica de componente, no qual são mostradas as imagens. O recurso de exportação para PDF foi implementado com a biblioteca iTextPDF ${ }^{2}$ que é utilizada para a criação de arquivos em PDF utilizando a linguagem de programação Java.

\footnotetext{
${ }^{1}$ https://www.youtube.com/user/incluirtecnologia

2 http://itextpdf.com/
} 


\section{Considerações Finais e Trabalhos Futuros}

O e-Sinais é um software educacional que tem o intuito de proporcionar aos surdos o aprendizado de novas palavras, o que permite a independência do tradutor/intérprete humano nas tarefas do dia a dia, seja na vida profissional ou acadêmica. O software possui dois relevantes recursos, a saber: (i) adição de sinais e (ii) exportação de sinais para PDF. Estes recursos viabilizarão, respectivamente, ampliar a base de dados com a inclusão de sinais inerentes de cada região e exportar os sinais para um arquivo PDF, o que possibilitará ao surdo estudar com um material digital ou impresso e compartilhar este material com outros surdos. Ademais, o material exportado poderá ser distribuído nas salas de aula e outros ambientes a fim de garantir a acessibilidade aos surdos. É importante ressaltar que o recurso de exportação de sinais para PDF não foi encontrado nos trabalhos correlatos. O e-Sinais também tem como utilidade o ensino de LIBRAS para pessoas ouvintes. Como trabalhos futuros, pretende-se adicionar mais palavras (simples e compostas) e seus correspondentes sinais ao banco de dados, permitir o armazenamento de palavras sinônimas e possibilitar ao usuário a seleção do sinal mais adequado. Também se tem o intuito de realizar um experimento com estudantes surdos, para corroborar a funcionalidade do software no ensino-aprendizagem da Língua Portuguesa escrita.

\section{Agradecimentos}

Agradecemos o apoio financeiro concedido pelo IFBA por meio do Programa Institucional de Bolsa de Iniciação Científica para o Ensino Médio (PIBIC-EM) - Edital No 03/2014/PRPGI e ao professor de português do IFBA, Sinval Araújo de Medeiros Júnior, pela revisão do artigo.

\section{Referências}

1. Souza, T.A.F. and Monteiro, M.S. (2008) Libras em Contexto: Curso Básico - Livro do Professor. WalPrint Gráfica e Editora, Rio de Janeiro.

2. ADAP. (2013) Deficiência Auditiva Atinge 9,7 milhões de Brasileiros, $\underline{\text { http://goo.gl/15pZVk. }}$

3. Oliveira, L.M.B. (2012) Cartilha do Senso 2010: Pessoas com Deficiência, http://goo.gl/AjeimR.

4. FENEIS. (2016) Federação Nacional de Educação e Integração dos Surdos, http://www.feneis.org.br/.

5. Carvalho, R.S. et al. (2013) LIBROL: Software Tradutor de Português para LIBRAS. In: ENCompIF, pages 2098-2101. CSBC.

6. Oliveira, J.P.S. (2012) ProDeaf: Uma Ferramenta Colaborativa para a Produção de Conhecimento em Libras. In: INES, pages 1-6, http://www.prodeaf.net/.

7. Nunes, M.G.V. et al. (2003) Projeto Pulo. USP, São Carlos.

8. Guarinello, A.C. et al. (2009) Surdez e Letramento: Pesquisa com Surdos Universitários de Curitiba e Florianópolis. Revista Brasileira de Educação Especial, 15, 99-120.

9. Silva, I.Q. et al. (2014) Avaliação da Compreensão de Textos Jornalísticos em Português, em LIBROL e em LIBRAS por Estudantes Surdos. In: II ENCompIF, pages 718-721. CSBC.

10. HandTalk. (2016) Hand Talk Tradutor para Libras, http://www.handtalk.me/.

11. Januário, G.C., Leite, L.A.F. and Koga, M.L. (2010) Poli-Libras: Um Tradudor de Português para Libras. 93 f. TCC (Bacharelado em Eng. da Comp.) - USP, São Paulo.

12. Moura, G. et al. (2013) Luz, Câmera, Libras!: How a Mobile Game Can Improve the Learning of Sign Languages. In Marcus, A. (Ed.), DUXU/HCII. LNCS, Springer, pages 266-275.

13. Santos, P.V. et al. (2015) Teaching Hand: Uma Plataforma Educacional para o Ensino da Língua Portuguesa para Crianças Surdas. In: IV CBIE - X LACLO, pages 441-446. CSBC.

14. Deitel, H.M. and Deitel, P.J. (2010) Java: Como Programar. Pearson, São Paulo.

15. HyperSQL. (2016) HSQLDB - 100\% Java Database, http://hsqldb.org/. 